\title{
PYLORIC LEIOMYOMA: BEHAVIOURAL ASPECTS IN A SHELTER DOG
}

\author{
Riccardo Benedetti ${ }^{1}$, Mirko Barabucci ${ }^{2}$, Alessandra Pigliapoco ${ }^{2}$, \\ Simona Cannas ${ }^{3}$, Clara Palestrini ${ }^{3}$ \\ ${ }^{1}$ Department of Environmental Science, University of Camerino, \\ Via Gentile III da Varano 62032 Camerino (MC), Italy \\ ${ }^{2}$ Veterinary Clinic "Pigliapoco, Leoni, Barabucci", C.da Valle 6, \\ 62100 Macerata (MC), Italy \\ ${ }^{3}$ Department of Veterinary Science and Public Health, University of Milan \\ Via Celoria 10, 20133, Milan, Italy
}

Received 9 April 2015; Received in revised form 10 June 2015; Accepted 12 June 2015

\begin{abstract}
The present report describes a case of pyloric wall leiomyoma in a shelter dog with a history of vomiting, pica, licking and chewing the walls of the kennel. The clinical, radiological, ultrasound, hematological and blood chemistry examinations showed no abnormalities. A compulsive oral disorder was diagnosed and treatment with behaviour therapy instigated. The compulsive oral behaviours stopped following behaviour therapy, however, the vomiting persisted, suggesting the need to proceed with further diagnostic exams. The ultrasound examination, repeated after 6 months, had revealed the presence of a hypoechoic mass $(3.52 \mathrm{~cm})$ in the pyloric-antrum obstructing the gastric outflow. Following gastric dilatation the mass was surgically excised. Histological examination revealed a pyloric leiomyoma. In clinical practice this case highlights the importance of gastrointestinal diseases in the development of behaviour changes related to pica.
\end{abstract}

Key words: dog, pica, gastrointestinal disease, compulsive disorders

\section{INTRODUCTION}

The term pica indicates the ingestion of non-nutritive and inedible substances, such as tissue, plastic, sticks and stones. Pica is most common in puppies, but can be also found in adult dogs. The behaviour of pica should be carefully evaluated for various reasons. First, because it may indicate the existence of an organic problem such as dental and/or oral disease, central nervous system disorders such as tumours or hydrocephalus, electrolyte imbalances, metabolic diseases, toxins, brain aging, cognitive dysfunction or gastrointestinal disorders

Corresponding author: Dr. Riccardo Benedetti, PhD

E-mail address: riccardo.benedetti@unicam.it

Present address: Department of Environmental Science,

University of Camerino, Via Gentile III da Varano,

62032 Camerino (MC), Italy

Phone: +393392725494

Copyright: $C 2015$ Benedetti R. This is an open-access article published under the terms of the Creative Commons Attribution License which permits unrestricted use, distribution, and reproduction in any medium, provided the original author and source are credited.

Competing Interests: The authors have declared that no competing interests exist.

Available Online First: 16 June 2015

http://dx.doi.org/10.14432/j.macvetrev.2015.06.047 and secondly, because it can have dangerous effects on the health of dogs and may cause intestinal obstructions or transmit parasitic diseases (1). Pica can be a disorder linked to learning and/or sometimes be a manifestation of an obsessive compulsive disorder (OCD) (2).

\section{CLINICAL CASE}

A female neutered, 12 year old, mixed breed dog had been housed in a shelter for 11 years. The dog presented with behavioural changes of one month duration, consisting of destruction and ingestion of the plastic and metal coating of the kennel, and vomitus consisting of food plastic and metal. The dog shared the kennel with another male neutered dog, 8 years old. The kennel was an area of $20 \mathrm{~m}^{2}$ which was partially covered. The kennels had an automatic watering bowl and the dogs were fed once a day, in the morning with fish and rice dog kibble. The dogs were exercised in a run area for an hour twice a week. During the clinical examination the dog showed on abdominal palpation, pain in 
the left hypochondric area. The examination of the oral cavity excluded dental and/or oral disease and the neurological examination was normal. A faecal examination was negative for parasites. A gastric foreign body was suspected due to the history of pica and vomiting. The diagnostic plan was to do a complete blood count, blood biochemistry, urinalysis, Leishmania testing (IFI), radiography and ultrasonography. A lateral and ventro-dorsal abdominal radiograph showed the presence of small radiopaque foreign bodies within the stomach. Symptomatic treatment was initiated consisting of pantoprazole(Nycomed SpA, Milano, Italy) $(1 \mathrm{mg} / \mathrm{kg}$ PO, SID for 5 days) and metoclopramide (Eurovet Animal Health, Ozzano dell'Emilia, Bologna, Italy) $(0.2 \mathrm{mg} / \mathrm{kg} \mathrm{SC}$, BID for 5 days), in order to protect the stomach and facilitate gastric emptying. During the treatment, the dog did not vomit and appetite was preserved. However, the dog continued to show pica accompanied with destruction of the kennel. Repeat radiological examination and ultrasonography were carried out, but no abnormalities were found. The dog was referred for a behavioural examination. The behavioural consultation excluded behaviours relating to cognitive dysfunction, typical of aging, and diagnosed an oral Compulsive Disorder (CD). The treatment was aimed to decrease stress, which may develop due to life in kennels $(3,4,5)$ and to enrich the environment where the dog lived. First, the dog and its dog kennel companion were moved to another kennel, where the surfaces were perfectly intact. The dog was also given the Kong ${ }^{\circledR}$ (Kong Company, LTD), a game dog food dispenser for mental stimulation at specific times of the day (periods during which there were no visitors and staff in kennels) and chewing bones for dogs were always available. The dog was given a daily routine which included an increase in exercise, which provided a daily output of at least one hour. During the following four months, the patient vomited with a frequency of 1-2 times per month but showed no more destructive behaviours or ingestion of inedible material, making extensive use of bones. The dog was presented to the clinic staff after six months with a decreased appetite and weight loss. A full blood count, biochemistry and urinalysis were performed. No abnormalities were detected in the complete blood count. Serum creatinine levels were increased $(2.54 \mathrm{mg} / \mathrm{dl}$; range $0.5-1.25 \mathrm{mg} / \mathrm{dl})$ and urea was increased (166 mg/dl; range $15-45 \mathrm{mg} / \mathrm{dl})$.

Urinalysis showed a specific gravity of 1.010 (range 1.025-1.035) and a protein:creatinine ration of 0:23. The patient was placed alone in a kennel, and 1 day later started vomiting and had a mild gastric dilatation. Ultrasound examination showed the presence of a hypo-echoic mass $(3: 52 \mathrm{~cm})$ at the 240 antrum of the pylorus blocking the gastric outflow. An ultrasound-guided fine needle aspirate was taken of the mass. Cytological examination was non diagnostic due to significant blood contamination. Two days later the dog showed an evident gastric dilatation and an emergency decompression and gastric lavage was performed. Later the mass was surgically excised and sent for histological examination. The histology report indicated a leiomyoma of the pyloric wall (Fig. 1) with large areas of necrosis and haemorrhage of an ischemic regressive character. The dog was followed up for a period of one year after the surgery. During this period there was no recurrence of the vomiting or pica and no abnormalities were detected in the serum creatinine levels, urea and urine specific gravity in the following biochemistry and urinalysis performed.

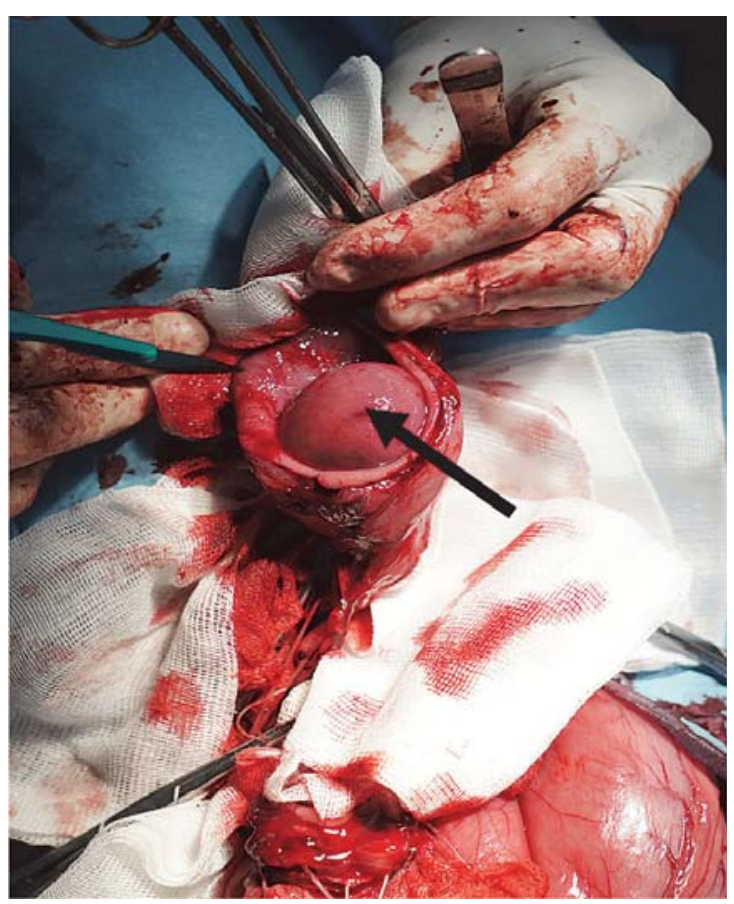

Figure 1. Pyloric leiomyoma: the arrow indicates the mass $(3: 52 \mathrm{~cm})$ at the antrum of the pylorus

\section{DISCUSSION}

Pica and the biting and/or licking of surfaces such as floors, carpets and finishes with a frequency, duration and intensity excessive compared to a normal exploratory behaviour, are often classified as compulsive disorders $(6,7,8)$. According to authors these repetitive and exaggerated behaviours can be caused by situations of conflict, stress and anxiety, and can be generalized out of this context and interfere with the daily activities $(7,8)$. Life 
Pyloric leiomyoma: behavioural aspects in a shelter dog

in kennels can have significant negative effects on the welfare of dogs causing physiological (9) and behavioural changes $(10,11,12)$ contributing to the development of potential CD (13) conditions. Pica should be considered primarily as a nonspecific sign that may be the consequence of several clinical conditions, including behavioural disorders (14).

In the submitted clinical case, though the CD disappeared because the dog was redirected to appropriate targets following the behavioural therapy, the persistence of the vomiting, the time lived in kennels, the sudden evolution and the age of the subject are factors that suggest the possible presence of an organic disease. In presentations of pica, in an adult or geriatric dog population, according with the existing literature, it is therefore necessary first to rule out differential diagnoses that take into account the presence of possible organic diseases (especially gastrointestinal) (15); only after having excluded the latter, will it be possible to direct the suspected diagnosis towards a compulsive behaviour.

\section{CONCLUSION}

In conclusion, the case report highlights the difficulty of a correct diagnosis and the importance of gastrointestinal disease in the differential diagnosis of pica in dogs. However, more investigations should still be done around pica in an adult or geriatric dog population, by finding a more significant sample data that can highlights further possible causes.

\section{REFERENCES}

1. Manteca Vilanova, X. (2003). Etologia clinica veterinaria del perro $y$ del gatto, 3th ed. (pp. 206-208).

2. Overall, K.L. (2001). Paure, ansie e stereotipie: condizioni specifiche che possono rientrare in una diagnosi di OCD; pica. In Prima Edizione Italiana, C.G. Edizioni Medico Scientifiche s.r.l, La Clinica Comportamentale del Cane e del Gatto (pp. 327). PMid:11605091

3. Coppola, C.L., Enns, R.M., Gradin, T. (2006). Noise in the animal shelter environment: building design and the effects of daily noise exposure. J Appl Anim Welf Sci. 9(1): 1-7.

http://dx.doi.org/10.1207/s15327604jaws0901_1 PMid:16649947
4. Sales, G., Hubrecht, R.C., Peyvandi, A., Milligan, S., Shield, B. (1997). Noise in dog kenneling: Is barking a welfare problem for dogs? Appl Anim Behav Sci. 52, 321-329.

http://dx.doi.org/10.1016/S0168-1591(96)01132-X

5. Gazzano, A., Mariti, C., Cozzi, A. et al. (2005). Modificazioni comportamentali nel cane ospitato in canile sanitario. Atti VI Congresso Nazionale So.Fi. Vet., 2-5 giugno, Stintino (Ss).

6. Landsberg, G, Hunthausen, W, Ackerman, L. (2003). Stereotypic and compulsive disorders. In: Handbook of behaviour problems of the dog and cat. (pp. 195-225). Saunders Ltd, Toronto, ON, Canada.

7. Luescher, A.U. (2003). Diagnosis and management of compulsive disorders in dogs and cats. Vet Clin North Am Small Anim Pract. 33, 253-267. http://dx.doi.org/10.1016/S0195-5616(02)00100-6

8. Tynes, V.V. (2008). Help! My dogs lick everything. Vet Med. 103, 198-211.

9. Hennessy, M.B, Voith, V.L, Mazzei, S.J. et al. (2001). Behaviour and cortisol levels of dogs in a public animal shelter, and an exploration of the ability of these measures to predict problem behaviour after adoption. Appl Anim Behav Sci. 73, 217-273. http://dx.doi.org/10.1016/S0168-1591(01)00139-3

10. Beerda, B., Schilder, M.B., Bernadina, W. et al. (1999). Chronic stress in dogs subjected to social and spatial restriction: II. Hormonal and immunological responses. Physiol Behav. 66, 243-254. http://dx.doi.org/10.1016/S0031-9384(98)00290-X

11. Wells, D.L., Hepper, P.G. (2000). Prevalence of behavior problems reported by owners of dogs purchased from an animal rescue shelter. Appl Anim Behav Sci. 69, 55-65. http://dx.doi.org/10.1016/S0168-1591(00)00118-0

12. Diesel, G., Pfeiffer, D., Brodbelt, D. (2008). Factors affecting the success of rehoming dogs in the UK during 2005. Prev Vet Med. 84, 228-241. http://dx.doi.org/10.1016/j.prevetmed.2007.12.004 PMid:18243374

13. Stephen, J.M., Ledger, R.A. (2005). An audit of behavioural indicators of poor welfare in kennelled dog in the United Kingdom. JAAWS 8 (2): 79-95.

14. Becuwe-Bonnet, V., Belanger, M.C., Frank, D. et al. (2012). Gastrointestinal disorders in dogs with excessive licking of surfaces. J Vet Behav. 7, 194-204. http://dx.doi.org/10.1016/j.jveb.2011.07.003

15. Myers, N.C., Penninck, D.G. (1994). Ultrasonographic diagnosis of gastrointestinal smooth muscle tumours in the dog. Veterinary radiology and ultrasound 35(5): 391-397. 